\title{
Fundamentos normativos para las políticas públicas interculturales
}

Normative foundations for intercultural policies

\author{
Edwin Cruz Rodríguez \\ Politólogo, Candidato a Doctor \\ en Estudios Políticos y Relaciones \\ Internacionales; miembro del Grupo \\ de Investigación en Teoría Política \\ Contemporánea, Universidad Nacional \\ de Colombia \\ ecruzr@unal.edu.co
}

\begin{abstract}
Resumen
Este artículo fundamenta las diferencias entre las acciones afirmativas y las políticas públicas interculturales desde una perspectiva normativa. El planteamiento central es que las acciones afirmativas son necesarias pero no suficientes para alcanzar los ideales del interculturalismo: el diálogo, el respeto, la convivencia y el aprendizaje mutuo entre culturas. A través de una lectura crítica de algunas obras de Will Kymlicka, el artículo contrapone los conceptos de multiculturalismo y de interculturalismo, destacando las limitaciones de aquél en la medida en que bajo el manto de una igualación formal de las diferencias culturales, el multiculturalismo y las acciones afirmativas que se inspiran en él, preservan la reproducción de las desigualdades entre los grupos portadores de las diversas formaciones culturales.
\end{abstract}

Palabras clave: multiculturalismo - interculturalidad - grupos étnicos - acciones afirmativas - políticas interculturales

\section{Abstract}

This paper accounts for the differences between affirmative action and intercultural policies from a prescriptive approach. Its central thesis purports that affirmative action is a necessary but not a sufficient tool in order to achieve the ideals of interculturalism, i.e. dialogue, respect, coexistence and mutual learning between cultures. Through a critical reading of the works of Will Kymlicka, the article conducts
Fecha de recepción 25.7.13

Fecha de aceptación 16.9.13 
a counterpoint between the concepts of multiculturalism and interculturalism, pointing to the shortcomings of the former since under the umbrella of a formal equalization of cultural differences multiculturalism and the affirmative action inspired, both contribute to the reproduction of the many inequalities among the groups activating the diverse cultural formations.

Key Words: Multiculturalism - interculturality - ethnic groups - affirmative action- intercultural policies

En este mundo no se consigue nunca lo posible si no se intenta lo imposible una y otra vez. Max Weber

\section{Introducción}

De ser un significante restringido a los discursos de los movimientos indígenas de distintos países, la interculturalidad ha pasado a convertirse en un término de uso común en la jerga administrativa. Aunque para algunos autores ello implica una moderación de su potencial crítico (Tubino 2005a: 85; Boccara 2012: 13), también indica que el proyecto normativo de la interculturalidad ha ganado un espacio relevante en las sociedades latinoamericanas.

Esa categoría se desarrolló desde principios de los años ochenta en la región, de la mano de las demandas de los pueblos indígenas por la educación intercultural bilingüe y planteó una crítica al enfoque multicultural que empezó a implementarse en reformas jurídicas y políticas estatales inspiradas en la influyente propuesta del filósofo canadiense W. Kymlicka (1996). ${ }^{1}$ Ambos términos, multiculturalismo e interculturalidad, revisten distintos significados dependiendo de contextos culturales y tradiciones de pensamiento. ${ }^{2}$ Aunque comúnmente se usan para designar la diversidad cultural en un contexto determinado (Walsh 2008: 140; Ainson 2007: 40-41; Tubino 2004a: 155; Requejo 1996: 94), tienen contenidos normativos claramente diferenciados.

Bajo la perspectiva multicultural se han afianzado las acciones afirmativas, como un mecanismo complementario a los derechos diferenciados en función de grupo, para alcanzar la justicia entre grupos étnicos y culturales. ${ }^{3}$ Del mismo modo, el creciente influjo de la categoría de interculturalidad ha llevado a la utilización del concepto "políticas interculturales" (Torres 2010). Sin embargo, no siempre se tienen en cuenta los contenidos normativos del enfoque intercultural para la acción pública estatal. Al contrario, 
frecuentemente se confunden las acciones afirmativas con las políticas interculturales. Este trabajo se ocupa de fundamentar esas diferencias desde una perspectiva normativa. Sostiene que las acciones afirmativas son necesarias, porque permiten conseguir mayores grados de equidad entre culturas, pero insuficientes para conseguir los ideales del interculturalismo: el diálogo, el respeto, la convivencia, el aprendizaje mutuo entre culturas, y la eliminación de las causas estructurales que producen la desigualdad entre ellas.

\section{El tamaño del grupo cultural, un criterio insuficiente}

Una primera diferencia entre ambos tipos de políticas tiene que ver con la orientación metodológica. Las acciones afirmativas están basadas en la distinción entre culturas mayoritarias y minoritarias. Al igual que el multiculturalismo de Kymlicka, suponen que siempre las culturas minoritarias son subordinadas y las mayoritarias dominantes. No obstante, no siempre rige esta lógica. Existen casos en los que las culturas subordinadas son mayoritarias y las minoritarias dominantes, así que el criterio del tamaño no es determinante para pensar este tipo de políticas públicas.

Para el multiculturalismo el problema son los enfrentamientos en torno a derechos lingüísticos, autonomía regional, representación política o símbolos nacionales, entre culturas o naciones minoritarias y mayoritarias (Kymlicka 1996:13). En las democracias liberales esas cuestiones se han dejado a decisión de las mayorías. Como consecuencia, las minorías han sido vulnerables a injusticias (Kymlicka 1996: 18). En este caso la relación de dominación entre culturas está determinada por su carácter mayoritario o minoritario.

Esta perspectiva del problema es útil para pensar las políticas públicas allí donde las relaciones de dominación entre culturas se estructuran según la lógica mayorías/minorías, como es el caso de las democracias occidentales desarrolladas, en las que se inspira el multiculturalismo de Kymlicka. Pero se ve desbordada en lugares como América Latina y otros contextos del sur global, donde el tamaño no determina las relaciones de poder entre grupos culturales.

En América Latina existen casos en los que las relaciones de desigualdad entre culturas no están definidas por su tamaño. Por ejemplo, en Guatemala y Bolivia, la mayoría de la población pertenece a las culturas indígenas. No obstante, estas culturas han sido históricamente dominadas y subalternizadas por la cultura mestiza, que se construyó desde el Estado como la cultura de la nación.

En contraste con el multiculturalismo, el interculturalismo latinoamericano está basado en la distinción entre culturas dominantes y subalternas, más que entre culturas mayoritarias y minoritarias. En la perspectiva de Catherine Walsh (2009: 28), América Latina se caracteriza por relaciones de desigualdad entre culturas legadas por la dominación 
colonial, que no necesariamente coinciden con el carácter mayoritario o minoritario de los grupos culturales, y que, siguiendo a Aníbal Quijano, denomina "colonialidad". La "colonialidad del poder" designa una estructura de poder heredada de la dominación colonial, pero se distingue del colonialismo, pues no implica solamente el dominio de un Estado de ultramar, sino un complejo dispositivo de poder basado en la idea de raza (Quijano 2000). Es un patrón de poder que se sustenta en la idea de raza como herramienta de jerarquización social.

Este concepto permite afirmar que existen sociedades pluriculturales que están dominadas por estados monoculturales, de tal manera que, en muchos de los países latinoamericanos, las élites blancas o mestizas han copado los lugares de poder y los estratos sociales altos, mientras que las antiguas “castas” de la Colonia, indígenas y afrodescendientes, están confinados a los estratos bajos y excluidos del ejercicio del poder público (Walsh 2009: 125).

En consecuencia, en aquellos países donde la cultura mestiza es mayoritaria, como podría ser Colombia o Ecuador, la colonialidad del poder puede concordar con la distinción entre minorías y mayorías. No obstante, en los casos en los que el mestizaje es menos marcado, como Guatemala o Bolivia, lo que existe es la dominación de una cultura minoritaria. En cualquier caso, la colonialidad del poder impide una relación dialógica y equitativa entre culturas, que es el horizonte normativo por el que apuesta el concepto de interculturalidad.

Las consecuencias de ambos enfoques para las políticas públicas son considerables. Mosquera et al. (2009: 76), después de analizar distintas definiciones de la acción afirmativa arriban a una concepción según la cual tales acciones son medidas de carácter temporal implementadas por el Estado para tratar desigualdades históricamente acumuladas, garantizar la igualdad de oportunidades o compensar costos provocados por la discriminación de determinados grupos, por motivos étnicos, religiosos, sexuales o de género, entre otros.

Así, en la perspectiva multicultural, la acción afirmativa se basa en la focalización de la acción estatal. Su formulación e implementación requieren una clara identificación de la población objeto y de las características que la definen frente a la sociedad mayoritaria. De forma que la acción afirmativa puede ser eficaz para conseguir la equidad entre los individuos miembros de grupos culturales discriminados donde sea posible focalizarlos, es decir, donde constituyan una minoría claramente identificable.

Sin embargo, su eficacia disminuye donde la mayoría de la población constituye una cultura subordinada, como en los casos antes mencionados. Ello se explica porque en estos casos no es posible focalizar claramente la población objeto y la acción afirma- 
tiva, por definición, no puede dirigirse a la mayoría de la población. En estos casos, se requiere otro tipo de medidas, orientadas al cambio estructural y a hacer equitativas las relaciones entre las culturas más que a integrar la cultura subordinada mayoritaria a los valores y formas de ser de la cultura dominante minoritaria.

\section{Más que políticas correctivas: acciones transformativas}

En segundo lugar, mientras la acción afirmativa está orientada a corregir las consecuencias de la desigualdad entre culturas -la discriminación, la exclusión-, apuntando a mejorar la igualdad de oportunidades, las políticas interculturales apuestan por atacar las causas de tal desigualdad. Buscan corregir las constricciones políticas, económicas y sociales que soportan la desigualdad cultural.

El multiculturalismo apunta a una igualdad formal entre culturas, basada en el reconocimiento de derechos y acciones afirmativas, según el caso. El ideal intercultural es más amplio: propugna por una igualdad sustancial que implica transformaciones estructurales para eliminar las inequidades sociales y económicas que impiden un diálogo equitativo entre culturas.

Kymlicka (1996: 15-16) discute con el supuesto liberal individualista según el cual para gestionar la diversidad cultural son suficientes los derechos individuales, pues la igualdad se entiende como iguales derechos para los individuos. ${ }^{4}$ Desde esa perspectiva, identidad étnica y creencias religiosas pueden expresarse libremente en el ámbito privado, pero no competen al Estado. Por el contrario, para Kymlicka (1996:157) el Estado puede ser laico, pero no neutral frente a las identidades étnicas y nacionales. En una democracia, las decisiones que el Estado adopta para tratar la diversidad cultural hacen que privilegie sistemáticamente la cultura mayoritaria (Kymlicka 1996: 80). Los liberales individualistas ignoran que los miembros de las minorías nacionales enfrentan desventajas que no afectan a la mayoría (Kymlicka 1996 156). La imparcialidad no consiste, entonces, en tratar todas las culturas como si fuesen iguales, sino en conceder a las minorías nacionales las mismas oportunidades que a la mayoría. Así se hacen más equitativas las relaciones entre culturas y se satisface un principio de justicia según el cual "todos los grupos nacionales tienen la posibilidad de mantenerse como cultura distinta, si así lo desean" (Kymlicka 1996: 160). La igualdad requiere un tratamiento diferencial que justifica los derechos de grupo y las acciones afirmativas, pues compensan las desigualdades que ponen en desventaja a los miembros de culturas minoritarias.

La interculturalidad comparte que el Estado no puede ser neutral y se requieren derechos de grupo y acciones afirmativas para conseguir la igualdad entre culturas, pero sus argumentos se alejan de la lógica mayorías/minorías. Dado que la colonialidad ordena jerárquicamente la sociedad por criterios raciales, el Estado es monopolizado por las élites blancas y mestizas que ocupan los lugares más elevados en esa estructura de poder. 
Sus políticas se presentan como universales y étnicamente neutrales, pero en realidad desconocen las desigualdades a las que se enfrentan las personas ubicadas en los estratos bajos (Walsh 2009: 79).

Sin embargo, la igualdad entre culturas por la que propugna la interculturalidad va más allá de la igualdad formal y el reconocimiento de derechos. Para Walsh (2006: 35; 2009: 43-44) la interculturalidad implica cambios estructurales. No se reduce a tolerar la diferencia dentro de las estructuras de la colonialidad establecidas, sino involucra profundas transformaciones, distribución del poder político y socioeconómico, que combatan la desigualdad entre culturas. La interculturalidad requiere cambios estructurales orientados a atacar las causas políticas y económicas de las desigualdades en las relaciones entre culturas, no sólo el reconocimiento de las diferencias (Tubino 2007a: 195-196). Implica una reinvención del Estado, la democracia y el modelo de desarrollo económico (Viaña 2010: 11-12). Como sostienen Viaña, Claros y Sarzuri (2009: 7) la interculturalidad, el problema de la convivencia entre culturas en términos igualitarios, no es un problema de "voluntad subjetiva", como lo pretende muchas veces el multiculturalismo, sino también de constricciones estructurales, políticas, económicas y sociales, que condicionan tales relaciones. De esa forma, el interculturalismo es una alternativa para articular las demandas por reconocimiento de la diferencia y por igualdad social o redistribución, una manera de atacar ambos tipos de injusticia (Fraser 1997: 18). No se plantea solamente el diálogo, sino al mismo tiempo encarar las condiciones en que este se desarrolla, las constricciones estructurales y las relaciones asimétricas de poder en las que tiene lugar: "hay que exigir que el diálogo de las culturas sea de entrada diálogo sobre los factores económicos, políticos, militares, etc., que condicionan actualmente el intercambio franco entre las culturas de la humanidad" (Fornet-Betancourt 2000: 12). No es posible separar la justicia cultural de la justicia social.

En un sentido similar a la justificación que Kymlicka acuña para los derechos diferenciados en función del grupo, las acciones afirmativas tratan de forma desigual a los grupos e individuos, para compensar, eliminar o cambiar, las prácticas que conllevan a la desigualdad y la discriminación, y de esa forma asegurar la igualdad (Cortez 2011: 285-286). Sin embargo, no pueden confundirse con políticas para erradicar la pobreza o conseguir una igualdad material sustancial; son medidas para asegurar la igualdad de oportunidades. En consecuencia, su meta es conseguir la igualdad en el acceso a bienes y servicios de las poblaciones discriminadas, de tal forma que se les garanticen los mismos derechos que al resto de la sociedad. Para ello comprenden incentivos que tratan de disminuir las desventajas sociales, políticas y económicas como las becas, cuotas o subvenciones, que igualmente realizan un tratamiento desigual para favorecer el grupo desfavorecido (Mosquera et. al. 2009: 81). En tal sentido, se rigen por criterios primordialmente cuantitativos. 
En cambio, las políticas interculturales permiten articular las acciones por la justicia social con la necesidad del reconocimiento de la diferencia. De acuerdo con Tubino (2007a: 195-196):

El multiculturalismo anglosajón formula y busca remediar el problema de la injusticia cultural como si fuera un problema aislado y aislable. Por ello promueve la sustitución de las políticas asimilacionistas de los Estados nacionales monoculturales por políticas de reconocimiento de las identidades, sin cuestionar el modelo económico vigente. Por el contrario, el interculturalismo latinoamericano se plantea el problema de la injusticia como un problema ligado al problema de la pobreza y la exclusión social. La injusticia cultural, sostenemos, no es sino la otra cara de la injusticia económica. Por lo tanto, si la exclusión económica y la discriminación cultural son dos fenómenos estrechamente interconectados, entonces las políticas de reconocimiento deben estar forzosamente acompañadas de políticas redistributivas.

Allí donde la mayoría de la población constituye una cultura subordinada se requieren, más que acciones focalizadas, cambios estructurales que eliminen las causas de la inequidad. Así pues, es necesario complementar las acciones afirmativas con "acciones transformativas", que no sólo ataquen las consecuencias de las relaciones asimétricas entre culturas en el corto plazo sino sobre todo sus causas en el largo plazo (Tubino 2011:13). Nancy Fraser (1997: 38), distingue las acciones afirmativas de las “acciones transformativas" de la siguiente manera:

Con soluciones afirmativas a la injusticia me refiero a aquellas soluciones dirigidas a corregir los resultados inequitativos de los acuerdos sociales, sin afectar el marco general que los origina. Por soluciones transformativas, por el contrario, entiendo aquellas soluciones dirigidas a corregir los resultados inequitativos, precisamente mediante la reestructuración del marco general implícito que los origina. El punto esencial del contraste es resultados finales versus procesos que los generan, no el cambio gradual versus el apocalíptico. 
En fin, las acciones positivas se orientan a gestionar las consecuencias de la discriminación, la exclusión o la opresión, mientras las acciones transformativas tratan de modificar el contexto social y estructural que las origina, sus causas.

\section{Coexistencia y tolerancia versus respeto y convivencia}

En tercera instancia, mientras las acciones afirmativas buscan la coexistencia, las políticas interculturales deben propender a la convivencia y el diálogo entre culturas.

El multiculturalismo pretende conciliar los valores de la filosofia liberal -tolerancia, libertad individual- con los derechos de grupo, necesarios para garantizar igualdad y justicia entre culturas. Se propone "acomodar" las diferencias nacionales y étnicas "de una manera estable y moralmente defendible” (Kymlicka 1996: 46). Así planteado, el multiculturalismo apuesta por la tolerancia y la coexistencia entre culturas. La tolerancia implica "soportar lo diferente" (Tubino 2003: 2). Ello quiere decir que la existencia del otro, lo mismo que el diálogo y el intercambio entre culturas, no se conciben como un bien en sí mismos; en algunos casos se entienden como un mal menor o en todo caso como algo no deseable. En consecuencia, las culturas pueden coexistir, pero de forma aislada, sin convivir. Tolerancia y coexistencia no suponen necesariamente el diálogo o intercambio entre culturas.

El concepto de interculturalidad también apunta a relaciones equitativas entre culturas, pero enfatiza en los intercambios y el aprendizaje mutuo entre ellas. Las relaciones y el aprendizaje tienen lugar cotidianamente donde existe diversidad cultural, pero en condiciones de desigualdad. La interculturalidad es un proyecto descolonizador: propugna porque desaparezca toda desigualdad entre culturas (Walsh 2009: 54; Esterman 2009: 52). Ello no implica erradicar los conflictos entre culturas, sino actuar sobre las estructuras que producen la diferencia como desigualdad y construir puentes de interrelación entre ellas (Walsh 2009: 46)

Interculturalidad significa "el contacto e intercambio entre culturas en términos equitativos; en condiciones de igualdad" (Walsh 2009: 14). El intercambio se refiere a la comunicación y el aprendizaje permanente entre personas y grupos con distintos saberes, valores, tradiciones y racionalidades, y se orienta a construir el respeto mutuo y el desarrollo de individuos y colectividades por encima de las diferencias culturales. El intercambio siempre es conflictivo, pero no se trata de suprimirlo sino de gestionarlo y orientarlo al desarrollo de las culturas y los individuos. Los seres humanos comparten muchos aspectos, lo cual permite el diálogo (Ramón 2009: 135). Se trata de romper con las relaciones de subordinación entre culturas para garantizar un "con-vivir" en condiciones de respeto mutuo. La interculturalidad "no tiene la pretensión de asumir la perspectiva del otro sino de permitir que la diferencia intervenga en uno, abriendo así nuevas perspectivas interculturales de vivir 'con' o 'con-vivir"” (Walsh 2009: 15). Es un 
enriquecimiento mutuo entre culturas que no implica diluir la identidad de los interlocutores para formar una síntesis única ${ }^{5}$.

En contraste con el multiculturalismo, el interculturalismo apuesta por el respeto y la convivencia entre culturas. Propugna por ir más allá de los derechos diferenciados y del aislamiento entre culturas, la tolerancia y la coexistencia, para producir un diálogo y un aprendizaje mutuo en condiciones de igualdad. La tolerancia multicultural no necesariamente implica diálogo y convivencia entre culturas. En cambio, el concepto de respeto implica que el intercambio con otras culturas y la convivencia son un bien en sí mismos y, por lo tanto, son deseables6. Como sostiene Tubino (2005a: 94), el multiculturalismo trata de producir sociedades paralelas, mientras la interculturalidad busca producir sociedades integradas y relaciones simétricas entre culturas:"las políticas multiculturales evitan los desencuentros. Las políticas interculturales promueven los encuentros. El multiculturalismo promueve la tolerancia, el interculturalismo el diálogo". El respeto no sólo conlleva la convivencia entre culturas, sino que promueve la necesidad de hacer equitativas tales relaciones a fin de conseguir el reconocimiento. De acuerdo con Tubino (2003: 10), "reconocer al otro es respetar su autonomía, es percibirlo como valioso. Pero la valoración a priori del otro es un falso reconocimiento. La gente merece y desea respeto, no condescendencia. El verdadero reconocimiento es a posteriori, se da en la experiencia del encuentro con el otro. Pero sólo es posible en relaciones auténticamente simétricas y libres de coacción".

La acción afirmativa se enfoca en la igualdad entre grupos, descuidando el intercambio y el mutuo aprendizaje, ideales de la interculturalidad. Aún más, su objetivo es favorecer la integración de los individuos o grupos discriminados, en igualdad de condiciones, a la sociedad o cultura mayoritaria. De ahí su carácter temporal y de corto plazo, pues se supone que en algún momento, cuando estos sujetos se integren y se supere la situación de discriminación, dejarán de ser necesarias. En otras palabras, las acciones afirmativas pretenden avanzar hacia una sociedad "ciega en materia de color" o pertenencia étnica, donde tales acciones no serían necesarias (Kymlicka 1996: 16-17).

Además, las acciones afirmativas son políticas principalmente para la equidad, no para la interculturalidad. Aunque mejoran la igualdad de oportunidades e introducen en la agenda pública temas de discriminación, generan tensiones que no necesariamente llevan a mejores formas de convivencia (Tubino 2007b: 91). Por ejemplo, las políticas de educación para grupos étnicos, aunque reconozcan derechos en el marco de las políticas de reconocimiento, contribuyen a la reproducción de representaciones racistas sobre poblaciones indígenas y negras (Rojas y Castillo 2007: 12).

En este sentido, las acciones positivas pueden fortalecer prejuicios, porque no están orientadas a mejorar las relaciones entre culturas, y a menudo producen "islas étnicas" (Tubino 2007a: 
195). Muchas veces refuerzan los estereotipos de los grupos a los que pretenden beneficiar. Por ejemplo, para subsanar la discriminación racial, toman la raza como criterio focalizador de poblaciones, aumentando los efectos de lo que quieren aminorar (Mosquera et. al. 2009: 84). Ello se explica principalmente porque están focalizadas exclusivamente en los grupos desfavorecidos o las culturas minoritarias, cuando el problema de la inequidad en las relaciones compete a ambos. La discriminación es una relación, si hay discriminados es porque hay discriminadores (Tubino 2005a: 90). Por lo tanto, para combatir la discriminación no sólo se deben hacer políticas para los discriminados, sino también para los discriminadores.

En fin, las acciones afirmativas son eficaces en promover el acceso de los excluidos a espacios de donde han sido discriminados. Sin embargo, ello no implica que la discriminación desaparezca. La hace visible, pero también puede reforzarla. Como afirma Fidel Tubino, no es suficiente con fortalecer la identidad de los excluidos o discriminados, es necesario trabajar en mejorar las relaciones entre culturas, la convivencia y no sólo la coexistencia:

Para que haya discriminación tiene que haber alguien que discrimina y alguien que es discriminado, alguien que estigmatiza y alguien que es estigmatizado. No basta con el fortalecimiento de la identidad de los discriminados para acabar con la discriminación; hay que cambiar las representaciones inconscientes sobre las cuales se han instalado patrones perversos de relación intercultural. $Y$ digo "perversos" porque se trata de relaciones que generan expectativas que no están en condiciones de satisfacer, que no pueden dar lo que ofrecen. Ofrecen reconocimiento $y$ no lo otorgan ni a discriminados ni a discriminadores. Los discriminados no son reconocidos porque no son ni respetados ni valorados en su identidad. Y los que discriminan obtienen un reconocimiento forzado, falso, porque para ellos, los discriminados no son personas, son cosas, medios. $Y$ el reconocimiento es, por definición, recíproco (2007b: 96).

Se requiere una "interculturalidad para todos", que empieza por una educación realmente intercultural que incluya los miembros de las culturas dominantes (Tubino 2004a: 154-155). No se trata de uniformizar las culturas, sino de preparar sus miembros individuales para la interacción en condiciones de respeto recíproco. Ello pasa por la construcción de un espacio neutral de relación entre culturas, una cultura pública común abierta a todas las diferencias, cuyos criterios sean acordados con base en el diálogo y en el consenso entre los diferentes grupos culturales, más que en la imposición de los valores de la cultura dominante. 
La educación intercultural bilingüe (EIB) constituye un claro ejemplo de las limitaciones de la acción afirmativa para construir la convivencia entre culturas. De acuerdo con Donoso et3 al. (2006: 25-27), la EIB, al formularse como una educación para grupos específicos, tiene dificultades para que los estudiantes allí socializados convivan con otros grupos en otros contextos. El discurso de la educación intercultural trata de generar una pedagogía de la diversidad para permitir el desarrollo de los pueblos indígenas y una coexistencia social armónica. Pero en la práctica se focaliza en lo indígena y, en vez de buscar la convivencia de las diversidades, pretende que los pueblos indígenas se integren a la sociedad nacional como ciudadanos abstractos.

Un caso arquetípico es el de Ecuador. En 1992 se oficializó el modelo EIB gracias a las gestiones y presiones de las organizaciones indígenas. Sin embargo, la reforma (Ley 150 de 1992) mantuvo un concepto de educación restringido a los indígenas y más que un modelo de educación intercultural se creó uno dual, con una Dirección Nacional de Educación Bilingüe, a cargo de las organizaciones indígenas, y una Dirección Nacional de Educación Hispana para hispanohablantes (Puente 2005: 15).

Algo similar pasa con el modelo de las universidades interculturales, que en la práctica funcionan como universidades para indígenas, con lo que se aíslan sus saberes en lugar de propiciar el diálogo con los de otras culturas. Alternativas interculturales podrían inspirarse en el "encuentro de saberes" implementado en la Universidad de Brasilia, que promueve el que maestros en saberes tradicionales impartan cátedra formal, con lo que entran a dialogar distintas lógicas de producción de conocimiento, como la oral y la escrita, además de especialistas en distintos saberes, académicos y no académicos (De Carvalho 2010: 242).

\section{Políticas dialógicas y participativas}

En cuarto lugar, por lo general, las acciones afirmativas están orientadas "desde arriba". Por ello, pese a que contribuyen a disminuir las brechas sociales, crean vínculos de dependencia que coartan la autonomía de las personas (Tubino 2003: 6). Así, corren el riesgo de producir un paternalismo estatal o de producir "una cultura de la compasión que consolida los prejuicios étnicos y culturales” (Tubino 2005b: 72-73). Su defecto es que aunque aportan a la inclusión de los excluidos no los prepara para la interacción cultural, no forma ciudadanos capaces de desenvolverse en contextos culturales hostiles (Tubino 2007b: 92).

Las políticas interculturales deben ser políticas participativas "desde abajo", que permitan un fortalecimiento de la sociedad civil y el diálogo entre las distintas culturas a fin de definir sus criterios. La interculturalidad, el diálogo en condiciones de respeto y convivencia con aprendizaje mutuo, es tanto un presupuesto de partida, como una consecuencia de las políticas interculturales. 
El objetivo es que la formulación misma de las políticas convoque el diálogo intercultural, no que se formulen e implementen verticalmente desde el Estado. Lo deseable es que exista un proceso de discusión y diálogo intercultural para definir las necesidades y anhelos de las poblaciones comprometidas en las políticas. El carácter participativo de las políticas interculturales alude al hecho de que no se pueden diseñar políticas sin preguntarle al otro sobre sus propias necesidades, deseos y sentires. No se pueden hacer políticas para la otredad sin preguntarle al otro.

El diálogo intercultural es una alternativa a la imposición de valores monoculturales. Requiere, por lo menos, tres condiciones que deben ser definidas entre las distintas culturas: igualdad, reciprocidad y rechazo de la coacción (Tubino 2004b). Estas condiciones son tanto requisitos previos como resultado del diálogo.

De acuerdo con Tubino (2003: 11), existen dos formas de concebir el diálogo intercultural: “como imagen ideal o como utopía realizable". En su primera acepción, implica terminar con los conflictos entre culturas y alcanzar una convivencia armónica. No obstante, esta perspectiva además de su naturaleza inevitable, desconoce el carácter dinamizador y enriquecedor del conflicto. Los intentos por alcanzar reconciliaciones definitivas entre los diferentes terminan por generar imposiciones autoritarias. Por tanto, el diálogo intercultural no debe apostar por la eliminación de los conflictos, sino porque sean manejados de forma razonable, que se haga de los conflictos un aspecto enriquecedor de los grupos e individuos que conforman las culturas. Es, en últimas, concebir el diálogo más como un proceso permanente que como un resultado definitivo, aceptar el proceso mismo como un horizonte abierto donde se está dispuesto a convencer y ser convencido. Como afirma Krotz (2008: 12),

el diálogo no es una técnica pedagógica que lleva a resultados conocidos de antemano por sus promotores $y$ operadores, sino que es un proceso abierto, cuyo fruto al inicio apenas se vislumbra y que puede deparar sorpresas insospechadas.

En fin, y siguiendo a Tubino (2009 156), a diferencia de las perspectivas basadas en el consenso, que tratan de generar acuerdos entre las distintas "doctrinas comprehensivas" o concepciones del bien, sin modificarlas, el diálogo intercultural genera cambios en dichas concepciones, valores y tradiciones de las personas y grupos. No se orienta a conseguir un consenso último sobre los principios que garantizarían la coexistencia, sino a forjar en el proceso formas de "convivencia razonable". Esta perspectiva privilegia el proceso mismo del diálogo, como un generador de convivencia intercultural, antes que los principios o criterios reguladores a los que se arribe, pues tales principios o criterios siempre podrán ser modificados de forma dialógica. 
Esos supuestos contribuyen a fundamentar la hermenéutica diatópica como una forma de adelantar el diálogo intercultural. Esta perspectiva supone una interpretación de la relación intercultural basada en la apertura del horizonte y, concretamente, en la ubicación entre los dos lugares o topoi de las culturas. Es un procedimiento que responde a la pregunta de cómo entender los valores y concepciones de una cultura desde el topos, los valores y concepciones, de otra. Ello implica intentar situarse entre ambas, de ahí su carácter diatópico.

Por hermenéutica diatópica entiendo una reflexión temática sobre el hecho de que el loci (topoi) de culturas históricamente ajenas hace problemático entender una tradición con las herramientas de otra, y el intento hermenéutico para superar esos golfos (Panikkar 1982: 77).

Su objetivo es "crear juntos nuevos horizontes de inteligibilidad recíproca, sin que pertenezcan de manera exclusiva a una cultura” (Anguiló 2010: 155).

Toda interpretación de otra cultura siempre estará incompleta, pues la otredad, en un sentido epistemológico, sólo es parcialmente accesible. Es imposible ver con los ojos que otro ve, o en términos de la hermenéutica diatópica, asumir por completo el topoi de la otra cultura. No obstante, como anteriormente se afirmó, el intento forja una empatía que modifica los valores y concepciones de ambos interlocutores y conlleva la formulación de acuerdos parciales de convivencia.

Según Santos (2002: 70), el diálogo intercultural se produce entre culturas diferentes que albergan sentidos incontrastables. Cada uno tiene entramados (topoi) fuertes, los cuales funcionan como lugares comunes o premisas para la argumentación y hacen posible la discusión, el intercambio de argumentos. Pero una condición para la interpretación es asumir el carácter incompleto de las culturas. Esta incompletud sólo puede apreciarse desde la perspectiva del otro, pues el punto de vista propio está marcado siempre por la intención de erigir su propia identidad como la identidad de la totalidad, su parte como el todo. De ahí que:

El verdadero punto de partida de este diálogo es un momento de descontento con la propia cultura, una sensación difusa de que la propia cultura no proporciona respuestas satisfactorias a mis dudas, perplejidades o expectativas. Esta sensibilidad difusa está vinculada a un saber vago y a una curiosidad inarticulada acerca de otras culturas posibles y sus respuestas. El momento de descontento incluye un entendimiento previo de la existencia y posible 
relevancia de otras culturas, y se traduce a una conciencia reflexiva de la incompletud cultural. El impulso colectivo o individual para un diálogo intercultural $y$, de ese modo, para la hermenéutica diatópica, empieza aquí (Santos 2002: 78).

El objetivo de la hermenéutica diatópica no es llegar a la completud, siempre inalcanzable, sino aumentar la conciencia de la incompletud entre los interlocutores. Para Santos (2002: 79), el progreso de la hermenéutica diatópica debería medirse en relación al grado en que hace que las culturas tomen conciencia de su incompletud. Es una conciencia autorreflexiva que "significa el reconocimiento en el diálogo de la incompletud cultural de la propia cultura como es vista en el espejo de la incompletud cultural de la otra”.

En consecuencia, como afirma Tubino (2009: 164), la hermenéutica diatópica es un proceso que no termina. Establece vínculos entre lo que en apariencia es inconmensurable. Pero implica siempre tener un pie en el topos propio y otro en el ajeno.

En este sentido, el hermeneuta adopta una actitud de trascendencia de la propia cultura para ubicarse en el "entre" de las culturas: "interpreta la visión del otro, y, al hacerlo, la recrea desde su topos cultural, que no es estático sino que está simultáneamente en proceso de cambio". Así, quien interpreta no sólo descifra unos significados dados, sino también los recrea o los resignifica a partir de su propio horizonte de sentido (Tubino 2009: 166). La comprensión del otro es, por ello, una comprensión de la cultura propia, del sí mismo (Tubino 2003: 3). La hermenéutica diatópica supone entonces un proceso distinto de producción del conocimiento, implica la creación de un saber producto de un proceso colectivo y participativo, nunca individual y monocultural (Santos 2002: 75-76), que puede ser implementado en mecanismos participativos para la formulación e implementación de las políticas interculturales.

\section{Pensar en el largo plazo}

Finalmente, las acciones afirmativas son de corto plazo y temporales; muchas veces tienen una función “analgésica”, para canalizar el malestar que produce la inequidad social entre culturas (Tubino 2005b: 56). Ello tiene que ver con su sesgo asimilacionista. Reconocen al otro discriminado como desigual y por ello se orientan a mejorar la igualdad de oportunidades para que pueda acceder a los espacios que le están vedados. Pero no lo reconocen como diferente, lo que requiere afirmar su diferencia al tiempo que se propende por alcanzar la equidad en las relaciones con miembros de otras culturas.

A diferencia del multiculturalismo de Kymlicka, cuyo criterio de justicia, como anteriormente se mencionó, es permitir que las culturas mantengan y desarrollen su cultura si así lo desean, el interculturalismo apuesta por un criterio de justicia basado en el 
reconocimiento del otro como igual y diferente al mismo tiempo. Las transformaciones estructurales orientadas a eliminar las causas de la desigualdad entre culturas no sólo son necesarias para que cada cultura mantenga su diferencia, sino también para un reconocimiento del otro como sujeto, como igual y al mismo tiempo diferente (Walsh 2009: 45). Este es el criterio de justicia entre culturas por el que apuesta el interculturalismo.

Reconocer a la otra cultura solo como igual puede equivaler a desconocer su particularidad y tomarla como idéntica a la cultura propia (asimilacionismo). Pero reconocerla solamente como diferente puede generar una relación de desigualdad entre culturas (colonialidad) (Todorov 2010: 293). Una relación justa implica reconocer la otra cultura como igual y diferente. No es suficiente con el criterio de justicia del multiculturalismo, permitir que una cultura conserve su particularidad si así lo desea, pues ello es compatible con una relación de desigualdad entre culturas. Una cultura subordinada puede mantener su especificidad sin que ello implique una relación equitativa con otras culturas, por ejemplo, en el régimen de castas indio. Una relación justa implica reconocer la otra cultura como igual y diferente a la cultura propia en forma simultánea.

Las acciones afirmativas propugnan por la igualdad entre culturas, pero no resaltan las diferencias. Su objetivo es hacer que los grupos culturales desfavorecidos se integren en igualdad de condiciones a la cultura mayoritaria, avanzando hacia una sociedad donde no es necesario el trato diferenciado a lo que es diferente, más que favorecer el desarrollo de la diversidad.

En contraste, las políticas interculturales suponen un reconocimiento de la diferencia en forma permanente. Por eso, deberían operar permanentemente. Una vez se mitigue inequidad entre grupos culturales, se requieren políticas que salvaguarden la diversidad cultural y preparen los distintos grupos para la interacción, para prevenir la opresión y la discriminación. Así se atenúa su sesgo integracionista. En fin, según Tubino (2005a: 94), las políticas interculturales son de largo plazo. Buscan transformar las estructuras simbólicas donde se desenvuelven las relaciones entre diferentes.

\section{Corolario}

Este trabajo se propuso fundamentar las diferencias entre las acciones afirmativas y las políticas interculturales desde una perspectiva normativa, sosteniendo que las primeras son necesarias pero no suficientes para alcanzar los ideales de la interculturalidad. Esta categoría plantea un enfoque alternativo al multiculturalismo formulado por Kymlicka, para conseguir la justicia entre grupos culturales.

Las acciones afirmativas, inspiradas en el enfoque multicultural, y las políticas interculturales no son mutuamente excluyentes. Por el contrario, las acciones afirmativas pueden 
contribuir a la equidad, el diálogo y la convivencia entre culturas además de complementar los derechos diferenciados en función del grupo necesarios para garantizar la justicia entre ellas. Más aún, por las limitaciones de recursos o de legitimidad, en algunos casos son las únicas alternativas posibles.

No obstante, desde la perspectiva intercultural la eficacia de la acción afirmativa es ambigua. Existen coincidencias entre ambas, pues buscan corregir las inequidades entre grupos culturales desde una perspectiva sustancial, no sólo formal como los derechos diferenciados. Sin embargo, las acciones afirmativas son necesarias pero no suficientes para alcanzar los ideales de la interculturalidad, el respeto, la convivencia, el diálogo y el aprendizaje mutuo entre grupos culturales. Existen grandes diferencias metodológicas, normativas y prácticas entre las dos formas de pensar las políticas públicas.

En consecuencia, se requiere un tránsito hacia las políticas interculturales, que ataquen las causas socioeconómicas de la desigualdad más allá de sus consecuencias; que no sólo se preocupen por suprimir la discriminación y facilitar la integración de los grupos culturales a la cultura dominante, sino que permitan el desarrollo de sus diferencias; que, en términos normativos, vayan más allá de la tolerancia y la coexistencia para alcanzar el respeto y la convivencia entre culturas; que involucren las diferentes culturas en su diseño e implementación en procesos dialógicos y participativos, y que funcionen a largo plazo o de forma permanente.

Finalmente, la interculturalidad debería fomentarse en los diversos sectores de la acción pública y erigirse en un enfoque transversal de las políticas públicas (Donoso et. al. 2006: 19). Como sostiene Zapata-Barrero (2008: 93-94), en el mundo contemporáneo las políticas públicas deben replantear el ideal universalista en que se soportó la intervención estatal durante buena parte del siglo XX y no sólo vincular criterios de redistribución, sino también de reconocimiento. 


\begin{abstract}
${ }^{1}$ Si bien la obra de Kymlicka no agota el multiculturalismo, es el enfoque que más influencia ha tenido en las políticas y reformas estatales en América Latina así como en los debates públicos. Por ello, en aras de simplificar el texto se centra en su perspectiva para reconstruir el enfoque multicultural.

${ }^{2}$ Por ejemplo, autores como Tapia (2010: 64-65) y Tubino (2004a: 157-158; 2008: 175; 2011: 10-12) distinguen varias formas de interculturalidad de acuerdo a su tendencia ideológica (colonial, de resistencia, neocolonial o neoliberal, funcional, crítica, entre otras).Varios autores han llamado la atención sobre la polivocidad del multiculturalismo en distintas tradiciones teóricas y disciplinares (Sartori, 2001: 126; Colom, 1999: 37; Hall, 2010: 582-618). A ello habría que aunar los distintos significados que ambos términos asumen en distintos contextos culturales y geopolíticos (Levey, 2012; Meer y Modood, 2012).

${ }^{3}$ Este trabajo se ocupa únicamente de las acciones afirmativas orientadas a grupos étnicos. Estas políticas no se especializan en los grupos étnicos, sino que tienen poblaciones objeto más amplias, pues están dirigidas a igualar la situación de discriminación a la que se ven sometidos distintos sujetos por su condición étnica, racial, sexual o de género, e incluso fisica.

${ }^{4}$ La intervención de Kymlicka plantea diferencias sustanciales con los liberales individualistas, por su defensa de los derechos diferenciados en función del grupo, pero también con los teóricos comunitaristas, pues también propugna porque los individuos miembros de los grupos culturales puedan cuestionar o revisar las concepciones de "vida buena" en la que aquellos están basados. Para la diferencia entre liberales y comunitaristas ver Papachini (1996: 231-261). Una síntesis del recorrido teórico de Kymlicka respecto de liberales y comunitaristas en Kymlicka (2002: 25-48).

${ }^{5} \mathrm{La}$ interculturalidad "sugiere un proceso activo y permanente de negociación e interrelación donde lo propio y particular no pierdan su diferencia, sino que tengan la oportunidad y capacidad para aportar desde esta diferencia a la creación de nuevas comprensiones, convivencias, colaboraciones y solidaridades. Por eso la interculturalidad no es un hecho dado sino algo en permanente camino, insurgencia y construcción" (Walsh, 2008: 141).

6 "No basta con un respeto que solo signifique el derecho declarado a existir. Semejante 'respeto' sería muy limitado y con razón algunos podrían considerarlo engañoso. Estamos hablando de un respeto que signifique tomar en serio las diferentes culturas, dando la oportunidad a quienes las practican de desarrollarlas en interacción con otras culturas" (Ansion, 2007: 44-45). Todorov (2010:221) sostiene que existen tres ejes de relación con el otro: a) desde el punto de vista axiológico ese otro puede percibirse como bueno o malo, inferior o superior a mí; b) desde la perspectiva praxeológica puede estar cerca o lejos, impulsarme a seguir sus valores o identificarme con él, asimilarlo a mí, imponerle mi imagen o, finalmente, ser neutral o indiferente; y c) en sentido epistémico se puede inferir si conozco o no la identidad del otro en una gradación infinita. Para el autor, entre estos tres planos existen relaciones pero no una implicación rigurosa. Por ejemplo, puedo conocer muy poco al otro y al mismo tiempo amarlo. Hasta cierto punto el concepto de respeto por el que propugna el interculturalismo implica una cierta alineación de los tres planos: el respeto sólo se produce una vez se conoce al otro, para ello es necesario entrar en relación con él y valorar esa experiencia como un bien en sí mismo.
\end{abstract}




\section{Bibliografía}

Anguiló Bonet, Antoni Jesús (2010) "Hermenéutica diatópica, localismos globalizados y nuevos imperialismos culturales: orientaciones para el diálogo intercultural". Cuadernos Interculturales 14: 145-163.

Ansion, Juan (2007) "La interculturalidad y los desafios de una nueva forma de ciudadanía”. En:VVAA Educar en ciudadanía intercultural. Lima: Universidad de la FronteraPontificia Universidad Católica del Perú, 2007: 37-62.

Boccara, Guillaume (2012) "La interculturalidad como campo social". Cuadernos interculturales 18: 11-30.

Cortez, Olivia (2011) “Acciones afirmativas para afrodescendientes: ¿un reconocimiento de justicia o redistribución de recursos? En J. Sánchez,V.Avendaño y D. Caicedo (eds.) Pueblos afrodescendientes y derechos humanos. Del reconocimiento a las acciones afirmativas. Quito: Ministerio de Justicia, Derechos Humanos y Cultos del Ecuador-Oficina del Alto Comisionado de las Naciones Unidas para los Derechos Humanos, 2011: 283-315. De Carvalho, José Jorge (2010) "Los estudios culturales en América Latina: interculturalidad, acciones afirmativas y encuentro de saberes". Tabula Rasa 12: 229-251.

Donoso Andrés, Rafael Contreras, Leonardo Cubillos y Luis Aravena (2006) “Interculturalidad y políticas públicas en Educación”. Estudios pedagógicos 1:21-31.

Esterman, Josef (2009) "Colonialidad, descolonización e interculturalidad. Apuntes desde la filosofia intercultural". En VVAA Interculturalidad crítica y descolonización. Fundamentos para el debate. La Paz: Instituto Internacional de Integración del Convenio Andrés Bello, 2009: 51-66.

Fornet-Betancourt, Raúl (2000) Interculturalidad y globalización. San José de Costa Rica: Editorial DEI.

Fraser, Nancy (1997) Iustitia interrupta. Bogotá: Universidad de los Andes.

Hall, Stuart (2010) “La cuestión multicultural". En Sin garantías. Trayectorias y problemáticas en estudios culturales. Bogotá-Lima-Quito: Envión Editores, UASB-IEP, 2010 582-618.

Krotz Esteban (2008) "La fundamentación de la idea de los derechos humanos en contextos multiculturales". Alteridades 35: 9-20.

Kymlicka, Will (1996) Ciudadanía multicultural. Buenos Aires: Paidós.

(2002) “El Nuevo debate sobre los derechos de las minorías”. En Ferran Requejo (ed.) Democracia y pluralismo nacional. Barcelona: Ariel, 1996: 25-48.

Levey, Geoffrey Brahm (2012) "Interculturalism vs. Multiculturalism: A Distinction without a Difference?”. Journal of Intercultural Studies 2: 217-224.

Meer, Nasar y Tariq, Modood (2012) "How does Interculturalism Contrast with Multiculturalism?”. Journal of Intercultural Studies 2: 175-196.

Mosquera, Claudia; Margarita Rodríguez y Ruby León (2009) “Las acciones afirmativas como medio de inclusión social. Énfasis conceptuales, polémicas frecuentes y experiencias de implementación en algunos países”. En: Claudia Mosquera y Ruby 
León (eds.) Acciones afirmativas y ciudadanía diferenciada étnico-racial negra, afrocolombiana, palenquera y raizal. Bogotá: Universidad Nacional de Colombia, 2009: 69-152.

Panikkar, Raimon (1982) "Is The Notion of Human Rights a Western Concept?". Diogenes 75: 75-102.

Papachini, Angelo (1996) "Comunitarismo, liberalismo y derechos humanos". En Francisco Cortés Rodas y Alfonso Monsalve Solórzano (eds.) Liberalismo y comunitarismo. Derechos humanos y democracia.Valencia: Edicions Alfons El Magnánim, pp. 231-261.

Puente Hernández, Eduardo (2005) El Estado y la interculturalidad en el Ecuador. Quito: Universidad Andina Simón Bolivar-Abya Yala-Corporación Editora Nacional.

Quijano, Aníbal (2000) "Colonialidad del poder y clasificación social". Journal of World-Systems Research 2: 342-386.

Ramón, Galo (2009) “¿Plurinacionalidad o interculturalidad en la Constitución?. En: Alberto Acosta y Esperanza Martínez (comps.) Plurinacionalidad: democracia en la diversidad. Quito: Abya Yala, 2009: 125-160.

Requejo Coll, Ferrán (1996) "Pluralismo, democracia y federalismo. Una revisión de la ciudadanía democrática en estados plurinacionales". Revista Internacional de Filosofía Política 7: 93-120.

Rojas, Axel y Elizabeth, Castillo (2007) "Multiculturalismo y políticas educativas en Colombia ¿interculturalizar la educación?”. Revista Educación y Pedagogía 48: 11-24.

Santos Boaventura de Souza (2002) "Hacia una concepción multicultural de los derechos humanos". El Otro derecho 28: 59-83.

Sartori, Giovanni (2001) La sociedad multiétnica. Pluralismo, multiculturalismo y extranjeros. México:Taurus.

Todorov, Tzvetan (2010): La conquista de América. El problema del otro. México: Siglo XXI. Torres, Víctor (2010) La acción pública intercultural. Abya Yala: Quito.

Tubino, Fidel (2003) Interculturalizando el multiculturalismo. Barcelona: CIDOB.

(2004a) "Del interculturalismo funcional al interculturalismo crítico". En Mario Samaniego Mario y Carmen Garbarini (comps.) Rostros y fronteras de la identidad. Temuco: Universidad Católica de Temuco, 2004a: 151-164.

(2004b) "La impostergable alteridad: del conflicto a la convivencia intercultural". En Luci Castro (ed.) Los desafíos de la interculturalidad. Identidad política y derecho. Santiago de Chile: Universidad de Chile.

(2005a) "La praxis de la interculturalidad en los estados nacionales latinoamericanos". Cuadernos interculturales 5: 83-96.

(2005b) "Entre el multiculturalismo y la interculturalidad: más allá de la discriminación positiva”. En: Norma Fuller (ed.) Interculturalidad y política: desafíos y posibilidades, 2005b: 51-76. Lima: RDCSP.

(2007a) "El interculturalismo frente a los desafios del pluralismo jurídico”. En: Caminos para la inclusión en la educación superior. Lima: Fondo editorial Fundación EQUITAS e IEP, 2007a: 190-209.

(2007b) "Las ambivalencias de las acciones afirmativas". En:VVAA Educar en ciudadanía 
intercultural. Lima: Universidad de la Frontera y Pontificia Universidad Católica del Perú, 2007b: $91-110$

(2009) “Aportes de la hermenéutica diatópica al diálogo intercultural sobre los derechos humanos”. En C. Monteagudo, F. Tubino (eds.) Hermenéutica en Diálogo. Ensayos sobre alteridad, lenguaje e interculturalidad. Lima: OEA-OEI-PUCP, 2009: 55-179.

(2011) "El nivel epistémico de los conflictos interculturales". Revista electrónica construyendo nuestra interculturalidad 6-7: 1-14.

Viaña Jorge, Claros Luis y Sarzuri Marcelo (2009) "Presentación”. En VVAA, Interculturalidad crítica y descolonización. Fundamentos para el debate. La Paz: Instituto Internacional de Integración del Convenio Andrés Bello, 2009: 7-8.

Viaña, Jorge (2010) "Reconceptualizando la interculturalidad". En Jorge Viaña, Catherine Walsh y Luis Tapia Construyendo interculturalidad crítica. La Paz: Convenio Andrés Bello, 2010: 9-61.

Walsh, Catherine (2006) "Interculturalidad y (de)colonialidad: diferencia y nación de otro modo". En: Desarrollo e interculturalidad, imaginario y diferencia: la nación en el mundo Andino. Quito:Textos y Formas-Academia de Latinidad, 2006: 27-43.

Walsh, Catherine (2008) "Interculturalidad, plurinacionalidad y decolonialidad: las insurgencias político-epistémicas de refundar el Estado”. Tabula rasa 9, 131-152.

Walsh, Catherine (2009) Interculturalidad, Estado, Sociedad. Luchas (de)coloniales de nuestra época. Quito: Universidad Andina Simón Bolívar-Abya-Yala.

Zapata-Barrero Ricard (2008) “Diversidad y política pública”. Papeles 104: 93-104. 